\title{
Improvement of arterial oxygenation using the double trunk mask above low flow nasal cannula: a pilot study
}

\author{
Frédéric Duprez ${ }^{1,2,3}$ (1) Simon Cocu $^{3} \cdot$ Alexandre Legrand $^{5} \cdot$ Serge Brimioulle ${ }^{4}$. Shahram Mashayekhi ${ }^{1}$. \\ Gokhan Bodur $^{6} \cdot$ Arnaud Bruyneel $^{3}$. Jean Roeseler ${ }^{2} \cdot$ Grégory Cuvelier $^{3} \cdot$ Grégory Reychler $^{2}$
}

Received: 8 August 2019 / Accepted: 10 February 2020

(c) Springer Nature B.V. 2020

To the Editor,

The Double Trunk Mask (DTM) is an original mask (Fig. 1) which boosts the Fraction inspired in Oxygen $\left(\mathrm{FiO}_{2}\right)$ during oxygen therapy with high flow nasal oxygen (HFNO) [1]. In a previous study, the association of the DTM over HFNO showed an increase of the $\mathrm{PaO}_{2}$ without $\mathrm{PaCO}_{2}$ increase despite an added dead space of $210 \mathrm{~mL}$ due to the mask and the trunks. It can be explained principally by the washing of the trunks by the high flow (until $60 \mathrm{~L} / \mathrm{min}$ ). However, few studies have examined the effect of DTM on $\mathrm{PaO}_{2}$ and $\mathrm{PaCO}_{2}$ during oxygen therapy at low flow. Indeed, the use of low flow oxygen should lead to a risk of $\mathrm{CO}_{2}$ rebreathing [2]. In fact, during expiration, the additional oxygen does not escape but is collected in the two trunks. During inspiration, the patient receives this oxygen-enriched gas mixture from the trunks instead of the air in the room. The DTM thus

This study is registered at ClinicalTrials.gov with the reference number NCT03457363.

Frédéric Duprez

frederic.duprez@condorcet.be

1 Department of Intensive Care, Epicura Hospital, Hornu, Belgium

2 Institut de Recherche Expérimentale Et Clinique (IREC), Pole de Pneumologie, ORL \& Dermatologie, Service de Pneumologie, Université Catholique de Louvain, Brussels, Belgium

3 Laboratory of Exercise and Movement, Provincial School of Hainaut HEPH-Condorcet, Tournai, Belgium

4 Department of Intensive Care, Erasme Hospital, Université Libre de Bruxelles, Brussels, Belgium

5 Department of Physiology, Physiopathology and Respiratory Readaptation, Health Institute, University of Mons, 20 Place du Parc, 7000 Mons, Belgium

6 Department of Intensive Care, Groupe Hospitalier de La Région de Mulhouse Et du Sud-Alsace, Mulhouse, France acts like a "reservoir" and results in increased $\mathrm{FiO}_{2}$. However, thanks to its dead space volume, the DTM could also contribute to increasing $\mathrm{PaCO}_{2}$ by increasing rebreathing phenomenon [2]. We, therefore, prospectively investigated the effects of the DTM and its dead space on arterial blood gases in hypoxemic patients already receiving low flow oxygen through NC.

The study was conducted in the ICU of the Epicura Hospital (Hornu, Belgium) between June and November 2018. Patients were eligible if they were at least 18 -years-old, had respiratory symptoms (labored breathing with using of accessory muscles of respiration and/or dyspnea and/ or tachypnea and/or hyperpnea), received oxygen via NC but remain hypoxemic $\left(\mathrm{PaO}_{2}<75 \mathrm{mmHg}\right)$ [3-5], and were not considered for intubation or tracheotomy. Exclusion criteria were COPD, hypercapnia $\left(\mathrm{PaCO}_{2}>45 \mathrm{mmHg}\right)$, heart failure, shock or hypotension (vasopressor therapy), obesity hypoventilation syndrome, and altered consciousness (Glasgow Coma Scale score < 13). Oxygenation was ensured through standard NC (model 1616-21, Convatec ${ }^{\mathrm{TM}}$, Auckland, New Zeeland) or through standard NC with an additional DTM. The DTM is made of an aerosol mask (model 01.000.01.120 (CE0123), Dahlhausen, Köln, Germany) and two corrugated tubes of $22 \mathrm{~mm}$ diameter and $15 \mathrm{~cm}$ length ("Trunks"-ref 13.801.01.016, Dahlhausen, Köln, Germany) inserted into the lateral holes of the aerosol mask (Fig. 1). Age, height, weight, heart rate, respiratory rate, arterial blood pressure, arterial blood gases, sepsisrelated organ failure assessment (SOFA) were collected upon admission. Patients were placed in a semi-recumbent position and were received oxygen at a rate initially adjusted to obtain a pulse oximetry $\left(\mathrm{SpO}_{2}\right)$ value equal to or above $90 \%$, and this then maintained unchanged during the investigation. Each patient went through three phases of $30 \mathrm{~min}$ : Phase 1: NC alone (NC).

Phase 2: NC+DTM over the NC (NC+DTM).

Phase 3: NC alone (NC). 

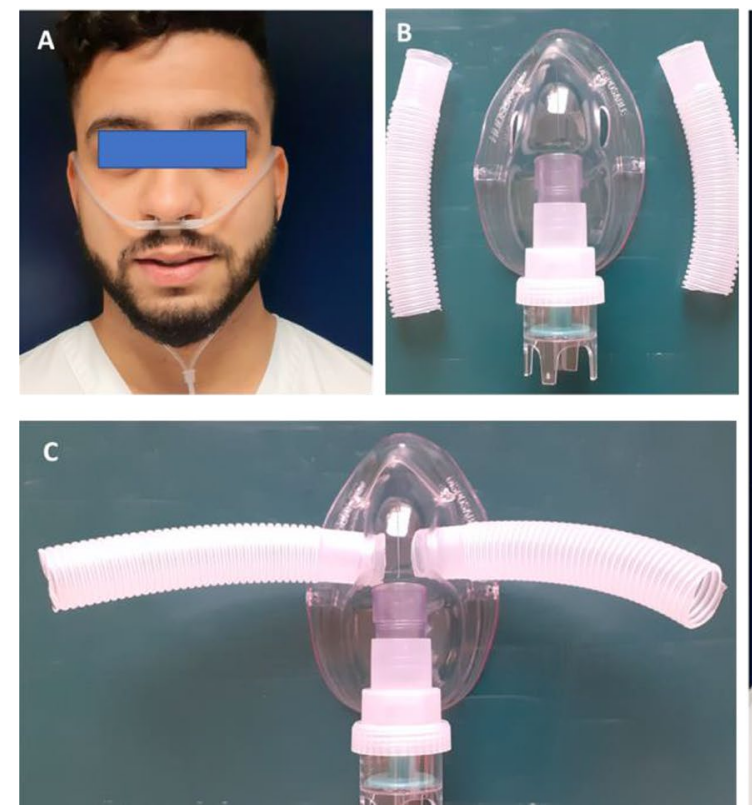

Fig. 1 a Subject with low flow nasal cannula (Convatec ${ }^{\mathrm{TM}}-\mathrm{New}$ Zealand-Auckland-ref. 1616-21). b Aerosol mask (Dahlhausen, Köln, Germany-ref: 01.000.01.120 (CE0123) with two corrugated tubing (Trunks) (ISO 22, $\pm 15 \mathrm{~cm}$ length). c Double Trunk Mask (DTM): Aerosol mask + two corrugated tubing ISO $22, \pm 15 \mathrm{~cm}$

The patients did not receive any instructions regarding opening or closing their mouths during the study. During the change of phase $1(\mathrm{NC})$ to phase $2(\mathrm{NC}+\mathrm{DTM})$ and then phase 3 (NC again), the oxygen flow was not significantly different. At the end of each phase, blood gases were collected again. Data were analyzed with SigmaPlot programs (Version 12.0, Systat Software Inc., London, UK). Data distribution was evaluated with the Kolmogorov-Smirnov

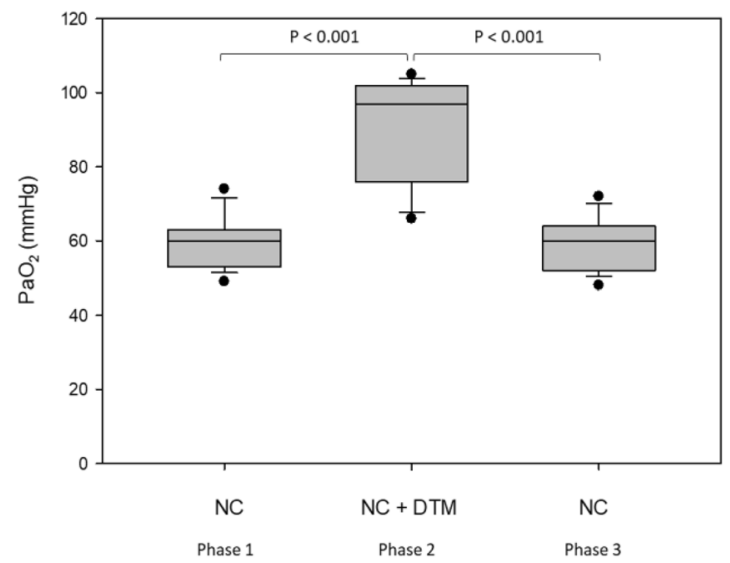

Fig. $2 \mathrm{PaO}_{2}$ and $\mathrm{PaCO}_{2}$ changes (Friedman test followed by a Tukey test) during the 3 experimental phases. The boxes show the median (P50) and the interquartile range (P25 and P75), the whiskers show the $\mathrm{P} 5$ and $\mathrm{P} 95$ percentiles, the dots represent outliers. $\mathrm{PaO}_{2}$ and $\mathrm{PaCO}_{2}$ increase significantly $(\mathrm{p}<0.001)$ with phase $2(\mathrm{NC}+\mathrm{DTM})$

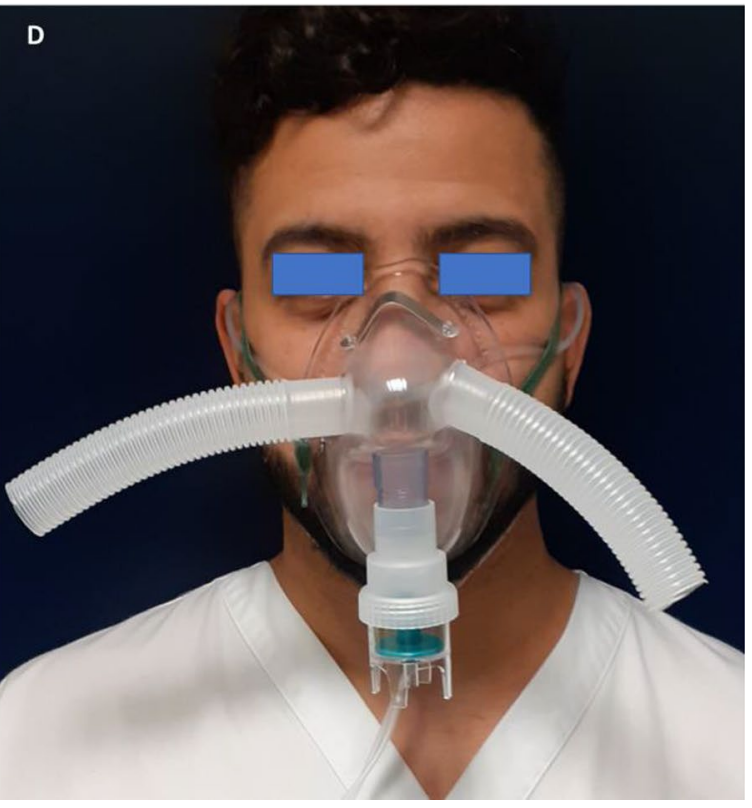

length inserted in the two lateral holes of the mask. d Subject equipped with DTM and nasal cannula. The DTM is just placed over the nasal prongs. Oxygen delivery is made through the nasal cannula and not into aerosol mask

test. Overall differences were tested by 1-way ANOVA for repeated measures for parametric data, and by a Friedman test for non-parametric data. In the presence of significant differences, comparisons between specific phases were evaluated with the Tukey test. A sample size of fifteen patients was calculated to detect a clinically significant difference in $\mathrm{PaO}_{2}$ increase at least $25 \%$ with an $\alpha$ of $5 \%$ at $80 \%$ power. Ten men and five women were included. The

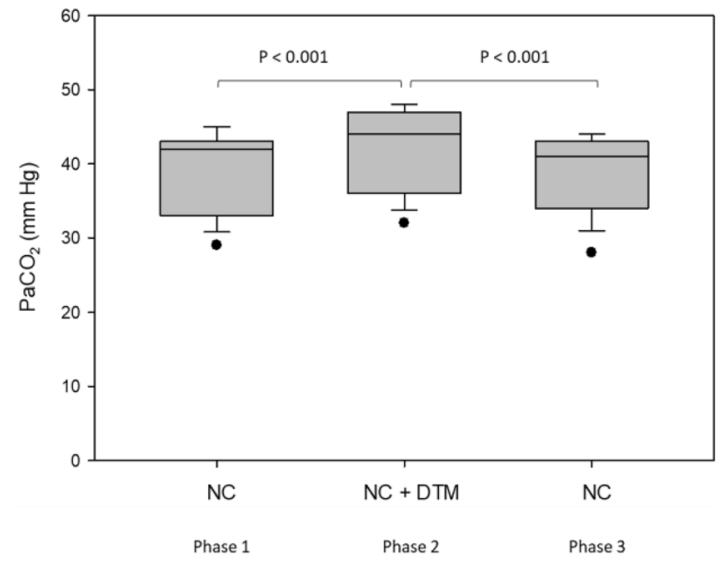

and returned to baseline after DTM removal. Between phases 1 and 3 , no statistical difference was found for $\mathrm{PaO}_{2}(\mathrm{p}=0.229)$ or $\mathrm{PaCO}_{2}$ $(\mathrm{p}=0.679)$. During phase 2 , we observed a clinically significant increase in $\mathrm{PaO}_{2}$ and a slight $(+3 \mathrm{mmHg})$ and not clinically significant increase in $\mathrm{PaCO}_{2}$ 
age was $69 \pm 14$ years, and the body mass index $27 \pm 8 \mathrm{~kg} /$ $\mathrm{m}^{2}$. The SOFA score was $6 \pm 2$ and the oxygen flow rate $5 \pm 3 \mathrm{~L} / \mathrm{min}$. Along the three study phases, $\mathrm{PaO}_{2}$ increased from $60 \pm 7 \mathrm{mmHg}$ (phase 1: NC) to $90 \pm 14 \mathrm{mmHg}$ (phase 2: $\mathrm{NC}+\mathrm{DTM}$ ) and then decreased to $59 \pm 7 \mathrm{mmHg}$ (phase 3: $\mathrm{NC})(\mathrm{p}<0.001)$. During these phases, $\mathrm{PaCO}_{2}$ increased from $39 \pm 5 \mathrm{mmHg}$ to $42 \pm 6 \mathrm{mmHg}$ and then decreased to $38 \pm 5 \mathrm{mmHg}(\mathrm{p}<0.001)$. Arterial $\mathrm{pH}$ decreased from $7.42 \pm 0.03$ to $7.39 \pm 0.03$ and then increased to $7.42 \pm 0.03$ $(\mathrm{p}<0.001)$. No statistical difference was found between phase 1 and phase 3 for $\mathrm{PaO}_{2}(\mathrm{p}=0.229)$ and $\mathrm{PaCO}_{2}$ $(\mathrm{p}=0.679)$ (Fig. 2). No statistical difference was found in the respiratory rate, heart rate, or mean arterial pressure.

Before experimentation, we expected a possible increase in $\mathrm{PaCO}_{2}$ due to the added dead space, to the Haldane effect and/or to a reduction of hypoxic pulmonary vasoconstriction. Several factors may contribute to the limited increase in $\mathrm{PaCO}_{2}$. First, leaks between the DTM and the face allow some expiratory flow to escape, thus reducing the amount of rebreathing. Second, the continuous oxygen flow could play a role in the dead space washing during the expiration period [2]. Third, Tidal Volume (Vt) may have increased to readjust the dead volume/tidal volume ratio [6-8].

Alternatives to DTM would be a non-rebreathing with reservoir bag (NRRB) or high flow nasal oxygen (HFNO). Comparisons between HFNO and NRRB suggest that HFNO improves oxygenation and dyspnea better than NRRB [9-13]. Fewer studies have compared DTM and NRRB. In two bench studies, DTM was more effective than NRRB in term of $\mathrm{FiO}_{2}[14,15]$. No confirmation has been obtained in clinical studies. One study has evaluated the impact of DTM in subjects receiving oxygen by $\mathrm{HFNO}: \mathrm{PaO}_{2}$ increased significantly with the DTM, while $\mathrm{PaCO}_{2}$ did not show any statistically significant difference [16].

The positive effects reported here should be confirmed in a larger study of patients with hypoxemic respiratory failure. The effects of DTM could also be evaluated during longer periods of application, in more severe COPD patients, in the obesity hypoventilation syndrome, during pre-oxygenation before intubation, in "do-not-intubate" patients, and possibly in mass casualty events (sudden increase in oxygen demand but limited resources).

It should be noted that severe hypoxemia is deleterious and is an indication for mechanical ventilation. The DTM is not recommended in patients with critical hypoxemia needing mechanical ventilation.

Summary In patients with hypoxemic respiratory failure, the association of the Double Trunk Mask with low flow nasal cannula increases the $\mathrm{PaO}_{2}$ significantly. The $\mathrm{PaCO}_{2}$ increases statistically, but the size effect is small and not clinically significant.

Data availability Additional unpublished data can be obtained by sending an e-mail to the corresponding author. To gain access, data requestors will need to sign a data access agreement.

\section{Compliance with ethical standards}

Conflict of interest The authors declare no conflicts of interest.

Ethical approval Thestudy protocol has been approved by the Erasmes Hospital (Brussels) Ethics Committee.

Informed consent Written consent was obtained from all the participants before inclusion.

\section{References}

1. Duprez F. The double trunk mask improves oxygenation during highflow nasal cannula therapy for hypoxemic acute respiratory failure. Respir Care. 2019;64:908.

2. Campkin NT, Ooi RG, Soni NC. The rebreathing characteristics of the Hudson oxygen mask. Anaesthesia. 1993;48(3):239-42.

3. Villar J, Slutsky AS. The incidence of the adult respiratory distress syndrome. Am Rev Respir Dis. 1989;140(3):814-6.

4. Wallaert B, Wemeau-Stervinou L, Salleron J, Tillie-Leblond I, Perez T. Do we need exercise tests to detect gas exchange impairment in fibrotic idiopathic interstitial pneumonias? Pulm Med. 2012;2012:657180.

5. Lumachi F, Marzano B, Fanti G, Basso SMM, Mazza F, Chiara GB. Relationship between body mass index, age and hypoxemia in patients with extremely severe obesity undergoing bariatric surgery. Vivo Athens Greece. 2010;24(5):775-7.

6. Van Meerhaeghe A, Sergysels R. Control of breathing during exercise in patients with chronic airflow limitation with or without hypercapnia. Chest. 1983;84(5):565-70.

7. Dunn WF, Nelson SB, Hubmayr RD. Oxygen-induced hypercarbia in obstructive pulmonary disease. Am Rev Respir Dis. 1991;144(3 Pt 1):526-30.

8. Abdo WF, Heunks LMA. Oxygen-induced hypercapnia in COPD: myths and facts. Crit Care Lond Engl. 2012;16(5):323.

9. Sztrymf B, Messika J, Mayot T, Lenglet H, Dreyfuss D, Ricard J-D. Impact of high-flow nasal cannula oxygen therapy on intensive care unit patients with acute respiratory failure: a prospective observational study. J Crit Care. 2012;27(3):324.e9-13.

10. Frat J-P, Thille AW, Mercat A, Girault C, Ragot S, Perbet S, et al. High-flow oxygen through nasal cannula in acute hypoxemic respiratory failure. N Engl J Med. 2015;372(23):2185-96.

11. Vargas F, Saint-Leger M, Boyer A, Bui NH, Hilbert G. Physiologic Effects of high-flow nasal cannula oxygen in critical care subjects. Respir Care. 2015;60(10):1369-76.

12. Brotfain E, Zlotnik A, Schwartz A, Frenkel A, Koyfman L, Gruenbaum SE, et al. Comparison of the effectiveness of high flow nasal oxygen cannula vs. standard non-rebreather oxygen face mask in post-extubation intensive care unit patients. Isr Med Assoc J. 2014;16(11):718-22. 
13. Rittayamai N, Tscheikuna J, Rujiwit P. High-flow nasal cannula versus conventional oxygen therapy after endotracheal extubation: a randomized crossover physiologic study. Respir Care. 2014;59(4):485-90.

14. Duprez F, Laghmiche A, Trimpont FV, Gatera E, Bodur G. Clinical evaluation of new ways of administration of oxygen: tusk mask II and double trunk mask. Prehosp Disaster Med. 2001;16(S1):S23-S2323.

15. Duprez F, Bonus T, Cuvelier G, Machayekhi S, Ollieuz S, Sonck $\mathrm{E}$, et al. Comparaison de la performance de trois masques à oxygène. Anesth Réanim. 2015;1:A314.
16. Duprez F, Bruyneel A, Machayekhi S, Droguet M, Bouckaert Y, Brimioulle $\mathrm{S}$, et al. The double-trunk mask improves oxygenation during high-flow nasal cannula therapy for acute hypoxemic respiratory failure. Respir Care. 2019;64(8):908-14.

Publisher's Note Springer Nature remains neutral with regard to jurisdictional claims in published maps and institutional affiliations. 